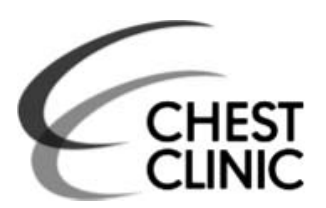

- An additional table is published online only. To view this file please visit the journal online (http://dx.doi.org/10.

1136/thoraxjnl-2011-201275).

${ }^{1}$ Department of Medicine, Johns Hopkins University School of Medicine, Baltimore, Maryland, USA

${ }^{2}$ Norwich Medical School, University of East Anglia, Norwich, UK

${ }^{3}$ College of Public Health, University of Arizona, Tucson, Arizona, USA

${ }^{4}$ Division of Public Health Sciences, Wake Forest School of Medicine, Winston-Salem, North Carolina, USA

\section{Correspondence to}

Dr Sonal Singh, Department of Medicine, 624 N Broadway, St $680 \mathrm{~B}$ and Baltimore, MD, 21205-1901 USA; sosingh@jhsph.edu

Received 24 October 2011 Accepted 7 June 2012 Published Online First 4 July 2012

To cite: Singh S, Loke YK, Enright $P$, et al. Thorax 2013, 68, 114-116.

\title{
Pro-arrhythmic and pro-ischaemic effects of inhaled anticholinergic medications
}

\author{
Sonal Singh, ${ }^{1}$ Yoon K Loke, ${ }^{2}$ Paul Enright, ${ }^{3}$ Curt D Furberg ${ }^{4}$
}

\section{ABSTRACT}

The majority of deaths in COPD are from cardiovascular causes. Several large randomized controlled trials demonstrate that inhaled anticholinergic agents ipratropium and tiotropium increase the risk of serious cardiovascular events, including cardiovascular mortality. Tiotropium Respimat is associated with a statistically significant increased risk of mortality (RR $1.52 ; 95 \% \mathrm{Cl}$ 1.06 to 2.16) and cardiovascular death (RR 2.05; 95\% Cl 1.06 to 3.99 ) compared with placebo in a metaanalysis of clinical trials. In the largest study, the subgroup of patients with COPD in the Respimat group with known rhythm and cardiac disorders at baseline had an especially high risk for cardiac death (RR 8.6; $95 \% \mathrm{Cl} 1.1$ to 67.2 ). Although there was no significantly increased risk of mortality (HR $0.89 ; 95 \% \mathrm{Cl}$ 0.79 to 1.02 ) or myocardial infarction (MI) (RR 0.73; $95 \% \mathrm{Cl} 0.53$ to 1.00 ) with tiotropium handihaler in the Understanding Potential Long-Term Impacts on Function with Tiotropium (UPLIFT) trial, the reported excess of angina (RR 1.44; $95 \% \mathrm{Cl} 0.91$ to 2.26), imbalance in strokes related to ischaemia and rates of supraventricular tachyarrhythmias are consistent with the pro-ischemic and pro-arrhythmic effects. The subjects at greatest risk of cardiovascular death, such as those with a recent history of MI, unstable or life-threatening cardiac arrhythmias or hospitalisation with heart failure, were excluded from the UPLIFT trial. The Prevention of Exacerbations with Tiotropium in COPD trial showed an excess of serious coronary ischaemic events of angina, myocardial ischaemia and MI with the tiotropium Handihaler compared with salmeterol. The authors urge caution in prescribing inhaled anticholinergics for patients with pre-existing arrhythmias or cardiac disorders.

\section{INTRODUCTION}

Chronic obstructive pulmonary disease (COPD) is the fourth leading cause of death in the USA, and the majority of these deaths are from cardiovascular causes. ${ }^{1}$ Since more than $80 \%$ of patients with COPD are cigarette smokers, they have a high prevalence of coronary artery disease. ${ }^{2}$ In addition, patients with COPD are generally older and the prevalence of undetected arrhythmias is substantial. ${ }^{2}$ A reduction in symptoms, primarily dyspnoea, and COPD exacerbations are the potential benefits of inhaled bronchodilators, including short-acting ipratropium bromide and long-acting tiotropium bromide, delivered as a dry powder (Spiriva Handihaler, Boehringer Ingelheim, Inc, Bracknell, UK) or via the new mist inhaler (Spiriva Respimat, Boehringer Ingelheim, Inc). These inhalers have not been demonstrated to alter the progressive decline in lung function or consistently improve survival in COPD. ${ }^{3}$ Despite its quaternary ammonium structure which limits diffusion, tiotropium is systemically absorbed as demonstrated by more than 10-fold increased risk of acute urinary retention, especially in older men. ${ }^{4}$ Ipratropium and tiotropium are actively transported through the bronchial epithelium using an organic cationic transporter (OCTN2), also present in the human heart. ${ }^{5}$ There is preliminary evidence that ipratropium may induce myocardial injury via mitochondrial dysfunction. ${ }^{67}$

\section{Pro-arrhythmic effects}

Anticholinergic drugs suppress parasympathetic control of heart rate which is associated with an increased incidence of tachyarrhythmias and myocardial ischaemia. ${ }^{8}$ Although tachyarrhythmias are often considered benign, they confer an increased risk of embolic strokes and sudden death in susceptible cardiac patients. ${ }^{9}$ At the time of regulatory approval, tiotropium was known to be associated with mild decreased heart rate variability, ${ }^{10}$ which is a known risk factor for cardiac mortality and sudden cardiac death. ${ }^{11}$ The Lung Health Study investigators reported a RR for hospitalisations due to supraventricular tachycardia of $4.5 \quad(95 \% \mathrm{CI}$ 0.97 to 20.8 ) associated with use of short-acting inhaled ipratropium versus placebo. ${ }^{12}$ The accurate prevalence of tachyarrhythmias in randomised controlled trials (RCTs) of tiotropium has not been reliably ascertained because $24 \mathrm{~h}$ Holter ECG monitoring was conducted in only a few small studies, ${ }^{13}{ }^{14}$ and resting 12-lead ECGs performed during clinic visits rarely detect them. However, despite these limitations, an increased risk of arrhythmias associated with tiotropium has been consistently reported in many clinical trials of both formulations. $^{3}{ }^{15-17}$ Furthermore, the large RCTs of ipratropium and tiotropium have shown a trend towards an increased risk of arrhythmias in comparison with placebo and other bronchodilator drugs. For example, the Understanding Potential Long-Term Impact of Tiotropium on Lung Function Trial (UPLIFT), a large 4-year study of the efficacy of the Spiriva Handihaler, reported relative risks of tachyarrhythmias of $3.70(95 \%$ CI 0.79 to 17.4) and atrial tachycardias of 7.39 (95\% CI 0.92 to 59) reported as adverse events. ${ }^{17}$ In a recent analysis of three placebo-controlled RCTs from the indacaterol development programme of patients who completed 24 h Holter ECG monitoring those randomised to tiotropium Handihaler had a RR of 
newly occurring, non-sustained ventricular tachycardia of 1.84 (95\% CI 0.89 to 3.43$)^{18}$

\section{Serious ischaemic cardiovascular effects}

In 2002 the Lung Health Survey reported that ipratropium increased the risk of cardiovascular death compared with placebo (RR 2.57; 95\% CI 1.08 to $6.15 ; \mathrm{p}=0.03$ ). ${ }^{12}$ In 2008 a meta-analysis of 17 RCTs of inhaled anticholinergics demonstrated a statistically significant increased risk (RR 1.60; 95\% CI 1.22 to 2.10) for the combined endpoint of stroke, myocardial infarction (MI) and cardiovascular deaths (including sudden death) with inhaled anticholinergic inhalers; the RR for allcause mortality was 1.29 (95\% CI 1.00 to 1.65$).{ }^{19}$ In 2011, a meta-analysis of five RCTs reported a statistically significant increased risk of all-cause mortality (RR 1.52; 95\% CI 1.06 to 2.16) and cardiovascular death (RR 2.05; 95\% CI 1.06 to 3.99 ) with tiotropium Respimat inhaler compared with placebo. ${ }^{20}$ In this meta-analysis there was a dose-response effect on all-cause mortality, which was primarily due to an excess of cardiac deaths. It was estimated that one excess death would be expected for every 124 patients treated with $5 \mu \mathrm{g}$ of tiotropium administered via the Respimat for 1 year.

In the largest Respimat study, patients with COPD in the Respimat group with known rhythm and cardiac disorders at baseline had an especially high risk for cardiac death (RR 8.6; 95\% CI 1.1 to 67.2 in those with rhythm disorders at baseline; RR 4.03; 95\% CI 1.15 to 14.13 in those with cardiac disorders at baseline). This risk was not statistically significant in patients with baseline use of cardiovascular medications (RR 1.62; 95\% CI 0.53 to 4.95 ) or a history of coronary artery disease (RR 1.08; 95\% CI 0.15 to 7.67$).{ }^{17}$ This observation is particularly important when the findings of no significant risk of mortality (HR 0.89 ; $95 \%$ CI 0.79 to 1.02 ) or MI (RR 0.73 ; $95 \%$ CI 0.53 to $1.00)$ with tiotropium in the UPLIFT trial are considered. The UPLIFT trial excluded patients with COPD with unstable arrhythmias, a history of heart failure, or a heart attack within the previous 6 months. Furthermore, the UPLIFT trial did not monitor adverse events for over $40 \%$ of participants who terminated treatment. Sudden deaths were categorised as 'general deaths' and not included as cardiovascular deaths. ${ }^{17}$ These design limitations reduced the ability of the trial to ascertain ischaemic and arrhythmic events. It is notable that the RR for serious adverse events for angina reported as a serious adverse event was 1.44 (95\% CI 0.91 to 2.26) with tiotropium in UPLIFT. ${ }^{3}$

The other significant recent study is the Prevention Of Exacerbations with Tiotropium in COPD (POET-COPD) trial $^{21} 22$ Patients with MI or congestive heart failure within a year, severe cardiovascular disease, those with cardiac arrhythmias or those with moderate to severe renal failure (creatinine clearance $>50 \mathrm{ml}$ ) were excluded from the trial. Although the trial was not adequately powered for individual cardiovascular endpoints an excess of angina pectoris (9/3707 vs 5/3669), myocardial ischaemia $(11 / 3707$ vs $6 / 3669)$ and MI events $(20 / 3707$ vs $13 / 3669)$ was noted with tiotropium Handihaler compared with salmeterol. This risk occurred despite a significant reduction in severe exacerbations of COPD with tiotropium.

In contrast to the sponsor's previous analysis of 29 placebo-controlled trials which reported an excess of stroke with tiotropium, ${ }^{17}$ UPLIFT reported no significant difference in the composite endpoint of number of patients with stroke with tiotropium (82 vs 80). ${ }^{16}$ This composite endpoint of all-cause stroke may have masked an imbalance in the potential risk of ischaemic stroke ${ }^{16}$ In another pooled analysis of three placebocontrolled RCTs, inhaled tiotropium Handihaler was the only
COPD drug (compared with formoterol or indacaterol) associated with a statistically significant increased risk of cardiovascular and cerebrovascular adverse events compared with placebo (RR $1.67 ; 95 \%$ CI 1.02 to 2.73$){ }^{18}$

The findings above should be viewed in the context of the overall results of arrhythmias and ischaemic cardiovascular events and mortality occurring in long-term trials of inhaled anticholinergics ( $>24$ weeks), as shown in online table 1, identified through systematic reviews and reviews of regulatory documents. ${ }^{17} 1920$ A significant increase in overall mortality with tiotropium Respimat is largely due to cardiovascular deaths. The tiotropium Handihaler and Respimat studies are consistently characterised by an increase in supraventricular arrhythmias and myocardial ischaemia manifest as angina in several large trials, including UPLIFT and the POET-COPD trial.

None of these trials were designed to measure cardiovascular outcomes and several long-term trials such as UPLIFT and POET-COPD excluded participants with cardiovascular risk. Incompleteness of reporting and incomplete ascertainment bias all the estimates towards the null. The absence of formal statistical significance in underpowered safety studies should not be construed as proof of safety. ${ }^{23}$

\section{CONCLUSIONS}

The inhaled anticholinergic agents ipratropium and tiotropium have the potential to increase the risk of serious cardiovascular events, including mortality, when used in the treatment of COPD. These findings have regulatory, scientific and clinical implications. Spiriva Respimat has not received regulatory approval in the USA because of an increased risk of mortality in clinical trials, but continues to be marketed in more than 55 countries. The Medicines and Healthcare Products Regulatory Agency in the UK has required a warning about the use of tiotropium Respimat in patients with cardiac rhythm disorders but not for other anticholinergics. ${ }^{24}$ Although an excess of angina and tachyarrythmias are noted on the current US label for the Spiriva Handihaler, ${ }^{16}$ and tachyarrhythmias are listed in the summary of product characteristics (European 6 label), ${ }^{15}$ neither label has any warnings or restriction regarding use of Handihaler in patients with cardiovascular disease. Thus the labels do not accurately capture or convey the extent and seriousness of pro-arrhythmic and pro-ischaemic risks associated with inhaled anticholinergic medications (Spiriva, Atrovent and Combivent, Boehringer Ingelheim, Inc).

Adequately powered cardiovascular safety trials of anticholinergic inhalers (short and long acting) are needed. Such trials should include objective tests of baseline cardiovascular disease; comprehensive ECG Holter monitoring at baseline and during follow-up; and complete ascertainment of the outcome measures of ischaemic cardiovascular events such as myocardial ischaemia, MI, ischaemic stroke and cardiovascular death (including sudden death) and all-cause mortality. This trial should include an enriched population of participants with a cardiac history to determine cardiovascular effects. There should be thorough objective monitoring for cardiovascular symptoms and consultation with cardiac specialists when necessary. We urge caution in prescribing inhaled anticholinergics for patients with pre-existing arrhythmias or cardiac disease. For each patient, the benefit of dyspnoea relief and reduction in COPD exacerbations should be weighed against the potential risks of serious cardiovascular adverse effects.

Atrovent, Combivent, Berodual, Spiriva Handihaler and softmist Respimat are registered trademarks of Boehringer Ingelheim, Inc. 
Contributors SS drafted the manuscript, acquired the data, and carried out the statistical analysis. All authors analysed and interpreted the data and critically revised the manuscript for important intellectual content. SS takes responsibility for the integrity of the data and the accuracy of the report and is guarantor.

Competing interests None.

Provenance and peer review Not commissioned; externally peer reviewed.

\section{REFERENCES}

1 Miniño AM, Xu JQ, Kochanek KD. Deaths: preliminary data for 2008. Nat/ Vital Stat Rep 2010;59. http://www.cdc.gov/nchs/data/nvsr/nvsr59/nvsr59_02.pdf (accessed 28 May 2012)

2 Curkendall SM, DeLuise C, Jones JK, et al. Cardiovascular disease in patients with chronic obstructive pulmonary disease, Saskatchewan, Canada. Ann Epidemiol 2006:16:63-70.

3 Tashkin DP, Celli B, Senn S, et al; for the UPLIFT Study Investigators. A 4-year trial of tiotropium in chronic obstructive pulmonary disease. $N$ Engl J Med 2008:359:1543-54

4 Kesten S, Jara M, Wentworth $C$, et al. Pooled clinical trial analysis of tiotropium safety. Chest 2006;130:1695-703.

5 Nakamura T, Nakanishi T, Haruta T, et al. Transport of ipratropium, an anti-chronic obstructive pulmonary disease drug, is mediated by organic cation/carnitine transporters in human bronchial epithelial cells: implications for carrier-mediated pulmonary absorption. Mol Pharm 2010;7:187-95.

6 Simmons K, Khan J, Hussan A, et al. Characterising cardiovascular safety profile of muscarinic antagonist, ipratropium. British Society for Cardiovascular Research 2010 Autumn Meeting: abstracts: 02. Heart 2011;97:e1.

7 Simmons $\mathrm{K}$, Hussain A, Maddock H. Further investigation into the cardiovascular safety profile of muscarinic antagonist, ipratropium. Proceedings of the British Pharmacologica/ Society. http://www.pa2online.org/abstracts/vol8issue1abst049p.pdf (accessed 24 Jun 2011).

8 van Vlymen JM, Parlow JL. The effects of reversal of neuromuscular blockade on autonomic control in the perioperative period. Anesth Analg 1997:84:148-54.

9 Mathew J, Hunsberger S, Fleg J, et al. Incidence, predictive factors, and prognostic significance of supraventricular tachyarrhythmias in congestive heart failure. Chest 2000;118:914-22.

10 Spiriva HandiHaler (Tiotropium Bromide) Inhalation Powder Company: Boehringer Inge/heim. 2004. Application No.: 021395. http://www.accessdata.fda.gov/ drugsatfda_docs/nda/2004/21-395_Spiriva.cfm (accessed 7 Oct 2011).

11 Bigger JT, Fleiss JL, Rolnitzky LM, et al. The ability of several short-term measures of RR variability to predict mortality after myocardial infarction. Circulation 1993:88:927-34
12 Anthonisen NR, Connett JE, Enright PL, et al; for the Lung Health Study Research Group. Hospitalizations and mortality in the lung health study. Am J Respir Crit Care Med 2002:166:333-9.

13 Covelli $\mathrm{H}$, Bhattacharya S, Cassino C, et al. Absence of electrocardiographic findings and improved function with once-daily tiotropium in patients with chronic obstructive pulmonary disease. Pharmacotherapy 2005;25: 1708-18.

14 Morganroth J, Golisch W, Kesten S. Eletrocardiographic monitoring in COPD patients receiving tiotropium. COPD 2004;1:181-90.

15 Electronic Medicines Compendium. Spiriva Respimat-Summary of Product Characteristics. 2011. http://www.medicines.org.uk/EMC/medicine/20547/PIL/Spiriva $\% 20$ Respimat\%202.5\%20micrograms\%20solution\%20for\%20inhalation (accessed 28 May 2012).

16 Boehringer Ingelheim. Briefing Document, Tiotropium-Pulmonary Allergy Drug Advisory Committee, November 2009. http://www.fda.gov/downloads/Advisory Committees/CommitteesMeetingMaterials/Drugs/Pulmonary-AllergyDrugsAdvisory Committee/UCM190466.pdf (accessed 12 Oct 2011).

17 Division of Pulmonary-Allergy Drugs Advisory Committee and Office of Surveillance and Epidemiology, US Food and Drug Administration. FDA Briefing Document. 2009. http://www.fda.gov/downloads/advisorycommittees/committeesmeeting materials/drugs/pulmonary-allergydrugsadvisorycommittee/ucm 190463.pdf (accessed 28 May 2012).

18 Worth $\mathrm{H}$, Chung KF, Felser JM, et al. Cardio- and cerebrovascular safety of indacaterol vs formoterol, salmeterol, tiotropium and placebo in COPD. Respir Med 2011:105:571-9.

19 Singh S, Loke YK, Furberg CD. Inhaled anticholinergics and risk of major adverse cardiovascular events in patients with chronic obstructive pulmonary disease: a systematic review and meta-analysis. JAMA 2008;300:1439-50.

20 Singh S, Loke YK, Enright PL, et al. Mortality associated with tiotropium mist inhaler in patients with chronic obstructive pulmonary disease: systematic review and meta-analysis of randomised controlled trials. Br Med J 2011;342 d3215.

21 Vogelmeier C, Hederer B, Glaab T, et al; POET-COPD Investigators. Tiotropium versus salmeterol for the prevention of exacerbations of COPD. N Engl J Med 2011;364:1093-103.

22 Tiotropium Once Daily 18 Mcg Versus Salmeterol Twice Daily $50 \mathrm{Mcg}$ on Time to First Exacerbation in COPD Patients. http://clinicaltrials.gov/ct2/show/NCT00563381? term=NCT00563381\&rank=1 (accessed 28 May 2012).

23 Greenland $\mathrm{S}$. Null misinterpretation in statistical testing and its impact on health risk assessment. Prev Med 2011;53:225-8

24 MHRA. Drug Safety Update Nov 2011; Vol 4: Issue 4: H2. http://www.mhra.gov.uk home/groups/dsu/documents/publication/con099854.pdf (accessed 28 May 2012). 